\title{
PRODUÇÃO E QUALIDADE DE SEMENTES DE CENOURA DAS CULTIVARES BRASÍLIA E CARANDAÍ ${ }^{(1)}$
}

\author{
ANTONIO ISMAEL INÁCIO CARDOSO ${ }^{(2)}$
}

\begin{abstract}
RESUMO
O presente trabalho teve por objetivo avaliar a produção e a qualidade das sementes obtidas de plantas de cenoura, das cultivares Brasília e Carandaí. O delineamento experimental foi em blocos ao acaso, com quatro repetições e cinco plantas úteis por parcela. Adotou-se o sistema semente-raiz-semente e indução floral por vernalização das raízes, durante 40 dias, a $5{ }^{\circ} \mathrm{C}$. Foram avaliados o número de umbelas, as produções de sementes por planta e por umbela, a massa ( $\mathrm{g}$ ) de mil sementes, a germinação e a primeira contagem de germinação em cada classe de umbela. A cultivar Brasília superou a Carandaí na produção de sementes por planta (52 g), em virtude da maior produção nas umbelas secundárias (38 g), e não diferiu da cultivar Carandaí quanto à produção nas umbelas primárias e terciárias. Nas demais características avaliadas não foram observadas diferenças entre as cultivares. A produção por umbela foi-se reduzindo sucessivamente das primárias (7,5 g por umbela) às secundárias ( $3,0 \mathrm{~g}$ por umbela) e às terciárias $(0,5 \mathrm{~g}$ por umbela). As sementes das umbelas primárias apresentaram maior massa (média de 2,1 g por mil sementes) em relação às secundárias (1,6 g por mil sementes) que, por sua vez, superaram as terciárias (1,4 g por mil sementes). As sementes das umbelas primárias e secundárias apresentaram maior poder germinativo comparativamemte às terciárias.
\end{abstract}

Palavras-chave: Daucus carota L., sementes, umbelas, produção, qualidade.

\section{ABSTRACT \\ YIELD AND QUALITY OF CARROT SEEDS FROM CULTIVARS BRASÍLIA AND CARANDAÍ}

The objective of the present work was to evaluate yield and quality of seeds on carrot cultivars Brasília and Carandaí. Four replications of five plants were set out in a randomized complete block design. The roots were planted after 40 days of vernalization at $5{ }^{\circ} \mathrm{C}$ and the seed harvesting was in October. Number of umbels, seed yield per plant and per umbel, 1.000 seed mass and germination, according to umbel order, were evaluated. Cultivar Brasilia had higher seed yield per plant (52 g), due to higher yield in secondary umbels $(38 \mathrm{~g})$, but not different from Carandaí in primary and tertiary umbels. Differences between cultivars were not observed in the other evaluated characteristics. Primary umbel had greater seed yield (7.5 g per umbel), followed by secondary ( $3.0 \mathrm{~g}$ per umbel) and tertiary was the least productive ( $0.5 \mathrm{~g}$ per umbel). Primary umbel seeds were heavier $(2.1 \mathrm{~g}$ per 1.000 seeds) than secondary (1.6 g per umbel) and secondary were heavier than tertiary (1.4 g per umbel). Seeds from primary and secondary umbels had better quality than tertiary umbel seeds.

Key words: Daucus carota L., seeds, umbels, yield, quality.

(1) Recebido para publicação em 31 de julho de 1998 e aceito em 10 de janeiro de 2000.

$\left({ }^{2}\right)$ Departamento de Horticultura, Faculdade de Ciências Agronômicas, Universidade Estadual Paulista, Botucatu, Caixa Postal 237, 18603-970 Botucatu (SP). E-mail: imaeldh@fia.unesp.br 


\section{Introdução}

No Brasil a cenoura classifica-se entre as hortaliças com maior volume de produção, tendo sido a quarta hortaliça em quantidade produzida no Estado de São Paulo em 1994, com 253.500 t (TRANI et al., 1997).

Para sustentar a área produtora, o País dependia da importação de sementes provenientes da Europa, Estados Unidos e Japão, a qual, em 1983, atingiu cerca de 100 toneladas. A partir dessa data, com o lançamento das cultivares Brasília e Kuronan, criou-se a opção de produção de sementes no Brasil possibilitando, a partir de então, uma sensível diminuição na sua importação (VIGGIANO, 1990). Tais cultivares nacionais, recomendadas apenas para o cultivo de verão nas Regiões Sul e Sudeste, apresentam boa resistência à queima das folhas, sendo, no entanto, muito suscetíveis ao florescimento prematuro (bolting) sob as condições de baixas temperaturas e de fotoperíodo crescente, prevalecentes durante o inverno e a primavera (CARdoso e Della Vecchia, 1995).

Atualmente existem cultivares nacionais selecionadas a partir de 'Brasília', com maior resistência ao florescimento prematuro ('Prima' e 'Carandaí'), recomendadas para semeadura na primavera/ verão.

Para produzir sementes das cultivares nacionais é necessária a indução ao florescimento por baixas temperaturas ou fotoperíodo crescente. A planta emite um pendão floral de até $1,5 \mathrm{~m}$ de altura que termina em uma inflorescência chamada umbela primária, ou de primeira ordem. Nas axilas foliares do pendão floral surgem ramificações laterais que sustentam umbelas chamadas secundárias. As hastes destas ramificam-se emitindo as umbelas terciárias. À medida que aumenta a ordem, as umbelas são cada vez mais numerosas e menores (BORTHWICK, 1931).

O tamanho, a longevidade e a germinação das sementes de cenoura variam de acordo com a cultivar, o lote e a época de produção. Tais diferenças têm sido associadas à densidade de plantas, ordem da umbela de origem e condições climáticas durante o desenvolvimento e a colheita das sementes (GRAY et al., 1988).

Nascimento (1991) relatou que as umbelas primárias, secundárias e terciárias contribuíram com $11,0 \%$, 58,0\% e 31,0\%, respectivamente, da produção total de sementes da planta na cultivar Brasília. As sementes provenientes da umbela primária apresentaram melhor qualidade que as das umbelas secundárias, e, estas, melhor que as das terciárias. Entretanto, não observou diferença significativa para a massa de mil sementes entre as umbelas das diferentes ordens. O número médio de umbelas por planta foi, respectivamente, de uma, onze e vinte e quatro, para primária, secundárias e terciárias.

Ainda com a cultivar Brasília, CASTRO e ANDREWS (1971) observaram que o número de umbelas de primeira, segunda e terceira ordens por planta foi de uma, onze e dezessete, respectivamente, ao passo que a contribuição para a produção de sementes foi de $13,6 \%, 71,4 \%$ e $14,9 \%$ respectivamente. Quanto à massa de mil sementes, relataram variações de $1,1 \mathrm{~g}$, 0,86 g e 0,79 g nas umbelas de primeira, segunda e terceira ordens respectivamente.

Diversos estudos têm demonstrado que a germinação das sementes pode variar de acordo com a ordem das umbelas de onde são colhidas. Sementes provenientes de umbelas de menor ordem apresentam, em geral, maior poder germinativo (BORTHWICK, 1931; Gray e Steckel, 1983; Nascimento, 1991; SzafiROWSKA, 1994).

Tendo em vista o lançamento de novas cultivares de cenoura selecionadas a partir da cultivar Brasília, o objetivo deste trabalho foi avaliar a produção e a qualidade das sementes produzidas, de acordo com a ordem da umbela, das cultivares Brasília e Carandaí.

\section{Material e Métodos}

O experimento foi realizado na Fazenda Experimental São Manuel, localizada no município de São Manuel (SP), e as avaliações foram realizadas no Laboratório de Sementes de Hortaliças do Departamento de Horticultura pertencente à Faculdade de Ciências Agronômicas da UNESP - Campus de Botucatu.

A semeadura das cultivares Brasília e Carandaí foi realizada em 20 de novembro de 1996 e a colheita das raízes, 100 dias depois. As raízes com massa entre 100 e $200 \mathrm{~g}$ foram vernalizadas a $4{ }^{\circ} \mathrm{C}$, durante 40 dias, e plantadas em 16 de abril de 1997 em espaçamento de $1,2 \mathrm{~m} \times 0,3 \mathrm{~m}$, caracterizando o sistema de produção semente-raiz-semente. A área experimental foi protegida, por todos os lados, pelo plantio de raízes que receberam o mesmo tratamento vernalizante. A colheita das sementes foi feita durante o mês de outubro de 1997.

$\mathrm{Na}$ colheita as umbelas foram contadas de acordo com a ordem (primária, secundária e terciária) e colhidas separadamente. Após a retirada das sementes (das umbelas) e sua limpeza, feita manualmente com o auxílio de peneiras para serem realizados o desaristamento e a separação das impurezas, as mesmas foram pesadas para cada ordem de umbela. A produção por umbela foi obtida dividindo-se a produção da ordem pelo seu número de unidades. Determinaram-se, em cada ordem, o peso de mil sementes (com uma amostra, ao acaso, por parcela), o vigor 
(teste de primeira contagem de germinação, aos 7 dias) e a germinação $\left(20^{\circ} \mathrm{C}\right)$ com contagem aos 14 dias (de acordo com as Regras para Análise de Sementes, Brasil, 1992). Para estes dois últimos testes foi utilizada uma amostra de 200 sementes de cada parcela, dividada em duas subamostras de 100 sementes em cada placa de Petri. Todas as análises laboratoriais foram realizadas após o armazenamento das sementes em câmara seca (umidade relativa de $40 \%$ ), e o teor de umidade das sementes foi estabilizado em $6 \%$ (determinado pelo método da estufa, Brasil, 1992).

Os tratamentos foram as cultivares e as ordens das umbelas. O delineamento experimental foi feito em blocos, ao acaso, com quatro repetições e cinco plantas úteis por parcela.

Com exceção da produção total de sementes por planta, em que apenas foram comparadas as cultivares, os dados obtidos foram analisados estatisticamente considerando cultivares, ordem das umbelas e a interação entre ambas, de acordo com MoRRISON (1990). As médias foram comparadas pelo teste $t$ de Student, utilizando-se o programa de análises estatísticas SAS (procedimento mixed).

\section{Resultados e Discussão}

Obteve-se interação significativa entre cultivares e umbelas nas análises da variância das características produção de sementes por umbela e produção de sementes por tipo de umbela. As características relacionadas à qualidade das sementes (massa de mil sementes, vigor e germinação aos 14 dias) apresentaram diferenças significativas apenas para o fator umbela.

Embora as duas cultivares não diferissem quanto ao número de umbelas por planta (média entre as duas cultivares de uma primária, dez secundárias e catorze terciárias, por planta), a cultivar Brasília apresentou maior produção de sementes por planta, como decorrência da maior quantidade de sementes por umbela secundária (Quadro 1).

Em todas as características avaliadas observou-se interferência do fator ordem da umbela. As umbelas primárias foram as que produziram, individualmente, a maior quantidade de sementes e as terciárias, a menor (Quadro 1). Esse resultado é explicado pelo fato de as primárias serem maiores e apresentarem menor quantidade de flores masculinas que as secundárias, as quais são maiores e apresentam maior quantidade de flores hermafroditas que as terciárias (BRAAK e KHO, 1958). Entretanto, ao se comparar a produção de sementes por planta, levando em conta a ordem das umbelas, observou-se superioridade das umbelas secundárias em relação às primárias e terciárias que não diferiram entre si (Quadro 1). Tais resultados concordam com os obtidos por CASTRO e ANDREWs (1971) na cultivar Brasília; entretanto, NASCIMENTO (1991) - também trabalhando com a cultivar Brasília e confirmando a superioridade da participação das umbelas secundárias na produção por planta - observou superioridade das terciárias em relação às primárias. A diferença pode ter sido devida ao maior número de umbelas terciárias ( 24 por planta) encontradas por este último autor, se comparado com 17 obtidas por CASTRO e ANDREWs (1971) e 13, no presente trabalho.

A superioridade da cultivar Brasília na produção de sementes por planta pode ser devida ao fato de a cultivar Carandaí contar com seis ciclos de seleção contra florescimento prematuro na cultivar Brasília, o que sugere a existência de correlação genética entre as duas características reprodutivas (resistência ao florescimento prematuro e produção de sementes por planta).

Quanto às características relacionadas à qualidade de sementes (massa de mil sementes, vigor e germinação aos 14 dias) não foram observadas diferenças

Quadro 1. Produção de sementes por planta e por umbela nas cultivares de cenoura Brasília e Carandaí, São Manuel (SP), 1997

\begin{tabular}{|c|c|c|c|c|c|c|c|}
\hline \multirow{2}{*}{ Cultivar } & \multicolumn{3}{|c|}{ Produção de sementes por umbela } & \multicolumn{3}{|c|}{$\begin{array}{c}\text { Produção de sementes por planta nas } \\
\text { umbelas }\end{array}$} & \multirow{2}{*}{$\begin{array}{c}\text { Produção total de } \\
\text { sementes por } \\
\text { planta }\end{array}$} \\
\hline & Primárias & $\begin{array}{l}\text { Secun- } \\
\text { dárias }\end{array}$ & Terciárias & Primárias & $\begin{array}{l}\text { Secun- } \\
\text { dárias }\end{array}$ & Terciárias & \\
\hline Brasília & $8,48 \mathrm{~A}$ a & $3,50 \mathrm{~A} \mathrm{~b}$ & $0,43 \mathrm{~A} \mathrm{c}$ & $8,48 \mathrm{~A} \mathrm{~b}$ & $37,94 \mathrm{~A} \mathrm{a}$ & $5,36 \mathrm{~A} \mathrm{~b}$ & $51,78 \mathrm{~A}$ \\
\hline Carandaí & $6,50 \mathrm{~A} \mathrm{a}$ & $2,59 \mathrm{~B} \mathrm{~b}$ & $0,47 \mathrm{~A} \mathrm{c}$ & $6,50 \mathrm{~A} \mathrm{~b}$ & $24,19 \mathrm{~B} \mathrm{a}$ & $7,86 \mathrm{~A} \mathrm{~b}$ & $38,54 \mathrm{~B}$ \\
\hline Média & 7,49 & 3,05 & 0,45 & 7,49 & 31,06 & 6,61 & 45,16 \\
\hline C.V. & & $28,5 \%$ & & & $21,3 \%$ & & $11,5 \%$ \\
\hline
\end{tabular}

Obs.: Médias, seguidas pela mesma letra maiúscula (colunas) ou pela mesma letra minúscula (linhas), não diferem estatisticamente pelo teste $\mathbf{t}$ ao nível de $5 \%$. 
Quadro 2. Massa de mil sementes e porcentagem de germinação, aos 7 e 14 dias, de sementes das umbelas primárias, secundárias e terciárias nas cultivares Brasília e Carandaí, São Manuel (SP), 1997

\begin{tabular}{|c|c|c|c|c|c|c|c|c|c|c|c|c|}
\hline \multirow[t]{2}{*}{ Cultivar } & \multicolumn{4}{|c|}{ Massa de 1.000 sementes } & \multicolumn{4}{|c|}{ Vigor (germinação aos 7 dias) } & \multicolumn{4}{|c|}{ Germinação (aos 14 dias) } \\
\hline & $\begin{array}{c}\text { Primá- } \\
\text { rias }\end{array}$ & $\begin{array}{l}\text { Secun- } \\
\text { dárias }\end{array}$ & $\begin{array}{c}\text { Terciá- } \\
\text { rias }\end{array}$ & Média & $\begin{array}{c}\text { Primá- } \\
\text { rias }\end{array}$ & $\begin{array}{l}\text { Secun- } \\
\text { dárias }\end{array}$ & $\begin{array}{c}\text { Terciá- } \\
\text { rias }\end{array}$ & Média & $\begin{array}{c}\text { Primá- } \\
\text { rias }\end{array}$ & $\begin{array}{l}\text { Secun- } \\
\text { dárias }\end{array}$ & $\begin{array}{c}\text { Terciá- } \\
\text { rias }\end{array}$ & Média \\
\hline & & & & & & & & & & & & \\
\hline Brasília & 2,18 & 1,63 & 1,45 & $1,75 \mathrm{~A}$ & 87,0 & 88,0 & 78,5 & $84,5 \mathrm{~A}$ & 88,0 & 89,0 & 80,0 & $85,7 \mathrm{~A}$ \\
\hline Carandaí & 1,95 & 1,57 & 1,41 & $1,65 \mathrm{~A}$ & 87,5 & 81,5 & 74,0 & $81,0 \mathrm{~A}$ & 88,0 & 84,0 & 77,0 & $83,0 \mathrm{~A}$ \\
\hline Média & $2,07 \mathrm{a}$ & $1,60 \mathrm{~b}$ & $1,43 \mathrm{c}$ & 1,70 & $87,2 \mathrm{a}$ & 84,7 a & $76,2 \mathrm{~b}$ & 82,7 & 88,0 a & 86,5 a & $78,5 \mathrm{~b}$ & 84,3 \\
\hline C.V. & & $6,1 \%$ & & & & $7,3 \%$ & & & & $6,7 \%$ & & \\
\hline
\end{tabular}

Obs.: Médias seguidas pela mesma letra maiúscula (colunas) ou pela mesma letra minúscula (linhas) não diferem estatisticamente pelo teste $\mathbf{t}$ ao nível de $5 \%$.

significativas entre as cultivares, embora houvesse uma tendência da cultivar Brasília de produzir sementes mais pesadas que as da cultivar Carandaí (Quadro 2).

Em média, para ambas as cultivares, observou-se que as sementes das umbelas de menor ordem são mais pesadas que as de maior ordem (Quadro 2). Essa relação decrescente foi similarmente relatada por outros autores (CASTRO e ANDREWS, 1971; SZAFIROWSKA, 1994); contudo, NASCIMENTO (1991) não observou diferença significativa para tal característica entre as diferentes ordens. Para a mesma cultivar Brasília, CASTRO e ANDREws (1971) obtiveram massa de mil sementes de 1,10 g, 0,86 g e 0,79 g para sementes das umbelas primárias, secundárias e terciárias respectivamente. Essas diferenças podem ocorrer, visto que a massa das sementes de cenoura varia de acordo com o lote e a época de produção, dentre outros fatores (GrAy et al., 1988).

As sementes das umbelas terciárias apresentaram vigor e germinação inferiores em comparação às das primárias e secundárias, as quais não diferiram estatisticamente entre si em ambas as cultivares (Quadro 2). Esse resultado deve estar relacionado à formação da semente, pois a massa da mesma pode ser indicativo de sua qualidade fisiológica. As sementes de maior tamanho ou as que apresentam maior densidade foram as mais bem nutridas durante o desenvolvimento e, normalmente, possuem embriões bem formados e com maiores quantidades de reservas, sendo potencialmente as mais vigorosas (CARVALHO e NAKAGAWA, 1983).

Os resultados indicam que a ordem da umbela foi o fator mais importante na qualidade das sementes, ao passo que a cultivar foi mais importante na quantidade de sementes produzidas.

Concluiu-se que a cultivar Brasília foi mais produtiva que 'Carandaí' e que as umbelas primárias foram as que produziram maior quantidade de sementes por umbela, seguidas das secundárias, e, por último, as terciárias. Quanto à qualidade, as sementes colhidas nas umbelas terciárias apresentaram menor vigor e poder germinativo; por sua vez, as sementes das umbelas primárias e secundárias não diferiram entre si.

\section{Referências Bibliográficas}

BRAAK, J.P.; KHO, Y.O. Some observations on the floral biology of the carrot (Daucus carota, L.) Euphytica, Dordrecht, v.7, p.131-139, 1958.

BORTHWICK, H.A. Carrot seed germination. Proceedings of American Society for Horticultural Science, Alexandria, v.28, p. 310-314, 1931.

CARDOSO, A.I.I.; DELLA VECCHIA, P.T. Considerações sobre o florescimento prematuro e suas implicações para o melhoramento de cenoura para primavera. Horticultura Brasileira, Brasília, v.13, n.2, p.146-149, 1995.

CARVALHO, N.M.; NAKAGAWA, J. Sementes: Ciência, Tecnologia e Produção. 2.ed. Campinas: Fundação Cargill, 1983. 429p.

CASTRO, L.A.B.; ANDREWS, C.H. Fatores influenciando o rendimento e a qualidade de sementes de cenoura (Daucus carota L.). Arquivo Universidade Federal Rural do Rio de Janeiro, Rio de Janeiro, v.1, n.2, p.19-28, 1971.

GRAY, D.J.R.A.;STECKEL, J.D. Some effects of umbel order and harvest date on carrot seed variability and seedling performance. Journal of Horticultural Science, Ashford, v.58, n.1, p. 73-82, 1983.

GRAY, D.J.R.A.; STECKEL, J.D.; BROCKLEHURST, P.A. Some effects of temperature during seed development on carrot (Daucus carota) seed growth and quality. Annals of Applied Biology, Wellesbourne, v.112, n.2, p.367-376, 1988.

MORRISON, D.F. Multivariate statistical methods. $3^{\text {rd }}$ ed. New York: McGraw-Hill, 1990. 495p. 
NASCIMENTO, W.M. Efeito da ordem das umbelas na produção e qualidade de sementes de cenoura. Revista Brasileira de Sementes, Brasília, v.13, n.2, p.131-133, 1991.

SZAFIROWSKA, A.I. The correlation between mother plant architecture, seed quality and field emergence of carrot. Acta Horticulturae, Wageningen, v.354, p.93-97, 1994.
TRANI, P.E.; GROPPO, G.A.; SILVA, M.C.P.; MINAMI, K.; BURKE, T.J. Diagnóstico sobre a produção de hortaliças no Estado de São Paulo. Horticultura Brasileira, Brasília, v.15, n.1, p.19-24, 1997.

VIGGIANO, J. Produção de sementes de cenoura. In: CASTELLANE, P.D.; NICOLOSI, W.D.; HASHEGAWA, M. Produção de sementes de hortaliças. Jaboticabal: FCAV/FUNEP, 1990. p.61-76. 